\title{
VALPARAÍSO, PATRIMONIO SUSTENTABLE
}

\author{
Pedro Serrano R. ${ }^{1}$
}

\section{Introducción}

La sustentabilidad no es un asunto fácil de definir, en especial si se refiere al habitar en las ciudades humanas. Existen claridades y definiciones en lo que respecta a los procesos generales de desarrollo: La sustentabilidad se define en función de lograr objetivos de desarrollo sin comprometer los recursos con que generaciones futuras puedan planificar y lograr sus propios objetivos en escenarios que aún no conocemos. La sustentabilidad requiere entonces un uso racional y responsable de todo tipo de recursos, sobre todo de aquellos de carácter no renovable, esto porque, justamente, la no renovabilidad es en sí una cara de lo insustentable. El patrimonio, entre otras cosas, tiene partes fuertemente no renovables; el patrimonio evoluciona con el tiempo. El patrimonio visto más allá de un museo de fachadas, monumentos o barrios, tiene una parte intangible que tiene que ver con la construcción de relaciones humanas, ambientes sociales y climas culturales asociados a la estructura física de la ciudad. Por lo anterior, la sustentabilidad de este patrimonio requiere de un esfuerzo notable de los habitantes durante generaciones. Una cosa es que una ciudad tenga un crecimiento sostenido en el tiempo, proceso conocido como desarrollo sostenido, y otra muy diferente es que la ciudad permanezca por los siglos desarrollando, entre otras cosas, un carácter sustentable que invita a vivir y permanecer en ella. 
De acuerdo a la información de la NU, los órganos rectores de los dos organismos de las Naciones Unidas responsables de los asuntos urbanos y ambientales han reconocido oficialmente al Programa de Ciudades Sustentables (PCS), ${ }^{2}$ servicio conjunto del PNUMA/CNUAH (Hábitat), como el instrumento clave para poner en práctica el componente ambiental del Programa de Hábitat y del Programa 21 a nivel de las ciudades.

\section{Amabilidad}

En términos de los habitantes de una ciudad, la sustentabilidad de los recursos tangibles e intangibles que la hacen permanecer en el tiempo está referida a la amabilidad de la misma, una ciudad amable es aquella susceptible de ser amada. Las formas de amar una ciudad son muchas y para sus habitantes permanentes, esta amabilidad está contenida en el tamaño, carácter y relaciones

1 Chileno, Ingeniero Electrónico,UTFSM 1976. Director de MECESUP0604, (USACH; UTFSM; UTALCA Y USERENA) para la sustentabilidad en la formación del arquitecto chileno. Presidente de Fundación Terram para el desarrollo sustentable www.terram.cl Desde 1996 fellow de Ashoka www.ashoka.org . Es coordinador de ARQ-X unidad de arquitectura de zonas extremas y académico en escuela de arquitectura de la UTFSM www.arq.utfsm.cl. Profesor parcial en UTEM.

Académico Planta del Departamento de Arquitectura UTFSMValparaíso Chile.

pedro.serrano@usm.cl que la ciudad mantiene con el clima, su entorno, sus sistemas de redes, servicios y por supuesto, los habitantes mismos. En estos sentidos hay ciudades amables desde muchos puntos de vista, pueden ser amables para el turista, para el sabio, el filósofo, el artista, el marino, el comerciante y los ciudadanos comunes y corrientes. Si existe en Chile una ciudad complejamente amada por sus habitantes y visitantes, esa es Valparaíso. Entender las razones por las cuales es y puede ser amada en el tiempo por sus habitantes, es comprender uno de los modos de hacer a Valparaíso una ciudad sustentable.

\section{Sustentabilidad}

Por otra parte, para incorporar el concepto de sustentabilidad a los procesos de una ciudad, es necesario agregar todos los factores técnicos y humanos que hacen que sus habitantes quieran vivir en ella en esta generación y que la ciudad siga

2 U.N.ABC de las Naciones Unidas, 2000, United Nations Publications, N.York, USA, Pag. 197. 
siendo deseable para generaciones venideras. Esto podría definirse como la habitabilidad sustentable de una ciudad: Una ciudad es sustentable en este sentido, en la medida que los habitantes que viven en ella, surgen, nacen o llegan a habitarla en el tiempo, quieren, desean, necesitan y aman permanecer en ella. El principal recurso al que recurre la sustentabilidad de la ciudad, mucho más allá que sus edificios, su energía o su agua, son sus habitantes y el tejido de sus relaciones. Las personas en el transcurso de las generaciones que habitan la ciudad son en sí renovables. En este sentido, el principal patrimonio renovable de la ciudad de Valparaíso está contenido en su gente y el tejido de sus relaciones y aquellas variables objetivas y subjetivas de la ciudad que ayudan a constituir el carácter del mismo. El habitante participa y construye su ciudad. Sustentar el patrimonio está íntimamente relacionado con sostener en el tiempo grados crecientes de participación ciudadana en el desarrollo de la ciudad que se desea.

Parte de Valparaíso ha logrado ser proclamada como un elemento más del patrimonio universal, ha sido capital cultural de la República de Chile, temas no menores que definen a una ciudad que podría ser más amable que otras. Pero esta amabilidad anclada en lo nostálgico, no es suficiente para determinar la sustentabilidad. De hecho, a pesar de ser Valparaíso una ciudad reconocidamente amada por muchos, en la hora de los recuentos estadísticos, presenta un retroceso interesante de su población. Las cifras del Instituto Nacional de Estadísticas indican cómo los más de 279 mil porteños contabilizados en el año 2000 han disminuido a unos 274 mil al año 2007. Perder población pareciera ser incongruente con el sentido mismo de hacer sustentable la ciudad. Por otra parte, una ciudad realmente amable, merece ser habitada por quienes la aman y no por cualquier persona. Cifras 2008 de MINVU con estimaciones sobre el crecimiento de los hogares en Chile para los próximos 4 años indican para Valparaíso una conservadora variación anual media de 0,543.

He aquí un punto notable para meditar profundamente: Valparaíso es amable fundamentalmente por aquello que la hace susceptible de ser patrimonio de la humanidad y merecer el nombre de capital de la cultura. A pesar de esto, muchos amantes ciudadanos deben emigrar hacia otras ciudades, porque la suya no es capaz de sostener sus necesidades de trabajo o porque la ciudad no abre ventanas a nuevas perspectivas de desarrollo. De acuerdo a lo anterior en las últimas décadas emigra lenta y constantemente parte de su patrimonio humano. Es un hecho que las ciudades no pueden vivir sólo de su estatus patrimonial,

3 Arriagada Luco, Camilo; Moreno Juan, El Crecimiento de los Hogares de Chile, MINVU, Santiago, Chile, 2008, pag. 43 y 56. 
se necesita desarrollar perspectivas ciudadanas, tecnología y oportunidades que se acerquen a las expectativas de calidad de vida de sus habitantes.

En esto hay que volver a recalcar que efectivamente lo interesante para el patrimonio de Valparaíso no es tan sólo la arquitectura de sus edificios, su relación con el mar, ni el urbanismo de sus calles, sino la trama social que todo esto y algo más genera, que hace la vida de sus habitantes positivamente entretenida, participativa, comunicada, llevadera y en definitiva amable. En estos momentos hay una suerte de expoliación de los habitantes antiguos y porteños de las zonas declaradas patrimoniales de Valparaíso. El llamado casco antiguo del puerto fue declarado Patrimonio de la Humanidad por UNESCO el año 2003, impulsando un fuerte movimiento de propiedades en él. Los habitantes antiguos, de bajos ingresos, ante la buena oferta económica, venden y están siendo reemplazados por pequeños hoteles, bares, "lofts" y casas modernizadas y remodeladas por dentro, que son ocupadas por extranjeros, intelectuales y nuevos habitantes en la moda de habitar en lo patrimonial. Estaría por verse si esta nueva cultura, sin el barrio social original, logra construir identidad en un viejo patrimonio físico del cual sólo quedan las fachadas. El tiempo podrá decir si este proceso resulta realmente sustentable.

\section{Energía, redes y sustentabilidad}

Más allá de todo esto, está la energía que ocupa la ciudad, sus usos y resultados, la pisada ecológica de sus habitantes y los límites de crecimiento físico que una ciudad puede mantener como sustentables en el tiempo. En general los textos sobre sustentabilidad hablan de estos temas físicos y se preocupan poco de si una propuesta de sustentabilidad, en términos energéticos y de recursos, resulte o no en una ciudad amable.

Después de haber dicho todo esto, es posible conjugar los parámetros físicos de la sustentabilidad con la amabilidad que la hace posible en el tiempo. Es fácil demostrar por qué una ciudad eficiente en energía es amable con sus habitantes. Es evidente que en esto hay un factor económico importante, la eficiencia energética se define como el poder hacer mejor las cosas usando menos recursos energéticos, lo que redunda en que resulta más barato, se contamina menos y las cosas se hacen efectivamente mejor. Si todo además se hace con energías renovables y limpias, entonces la eficiencia energética apunta precisamente a la sustentabilidad.

Una ciudad eficiente en energía es, por ejemplo, una ciudad concentrada, que permite a sus 
habitantes cumplir sus rutinas y sus sueños en trayectos cortos. Lo contrario de esto es una ciudad extensa, con trayectos interminables, que somete a sus habitantes a locomociones insoportables, tal como es el caso de Santiago de Chile y muchas otras urbes del planeta. Las redes de servicios extensas tampoco han demostrado ser sustentables. Transportar electricidad a grandes distancias, por ejemplo, involucra más cables, mayores pérdidas por transmisión, mayor costo de mantención, en resumen, muchos aportes a la insustentabilidad energética.

Una ciudad también se define por sus redes físicas, que no sólo conectan los sistemas superficiales y expuestos como sus calles y sistemas de transporte. Existe en las ciudades modernas una cantidad creciente de redes y servicios que construyen una compleja trama de líneas y ductos, que transportan precisamente aquellas cosas que complementan la calidad de vida y que hacen atractivas las ciudades para el ciudadano. Aquel ciudadano que busca básicamente un tipo de conectividad que sólo una ciudad moderna le puede entregar. El abrir una llave y que salga agua filtrada, clorada y purificada, el levantar un artefacto y poder comunicarse con el planeta, el apretar un botón y mágicamente obtener luz, movimiento, sonido, imagen. El ciudadano busca también deshacerse con eficiencia de sus aguas usadas y de sus residuos sanitarios, necesita que le retiren su basura, necesita información de todo el planeta al tiempo que desea que las aguas de las lluvias escurran bien, pronto, y no inunden su ciudad.

Más de once redes funcionales es posible de identificar en una ciudad moderna; algunas de ellas llegan a constituirse en patrimonio construido de la ciudad, como lo es el caso del sistema de cloacas de la ciudad de París. Algunas de estas redes funcionales, sobre todo las de comunicaciones, están hoy desarrollándose electromagnéticamente, trayendo la nueva imagen urbana de las antenas de todo tipo sembradas por doquier. Mantener optimizar y desarrollar las redes funcionales es también parte de la sustentabilidad de la ciudad.

Las redes funcionales incluso pueden afectar nefastamente el patrimonio construido, como ocurrió el 2007 en Valparaíso: La red eléctrica, demasiado cerca de la red de gas, carcomió las cañerías debido a una filtración conductora de la red sanitaria, salió mucho gas, muchos días y finalmente una chispa, eléctrica, generó una mortal explosión e inició uno de los incendios más grandes del último tiempo en la ciudad. Las llamas destruyeron buena parte del plan patrimonial de Valparaíso. La destrucción fue poco controlada en parte, porque la red de aguas para incendios tampoco funcionaba óptimamente.

Las ciudades sustentables debieran tener una densidad que permite una concentración en la 
extensión y control de sus redes. Las ciudades extensas latinoamericanas se desarrollan en uno o dos pisos de altura promedio, por espacio de kilómetros en sus periferias. Valparaíso por su parte es geográficamente concentrado, esta concentración se ve favorecida por la pendiente y su forma de cuenca natural, con un límite alto y una orilla de mar. Es probable que con un piso más en la media de su edificación, Valparaíso pueda sostener amablemente el doble de su actual población, sin cambiar los contornos territoriales. Los límites naturales de la ciudad ayudan a proyectar un futuro no muy extenso y las extensiones superficiales que vienen, se harán en conurbaciones que no serán Valparaíso. Crecen las ciudades satélites, pero no estos particulares límites urbanos generados por una particular geografía.

Elgran escenario anfiteatro que conforma Valparaíso apunta radialmente hacia una superficie horizontal allá abajo, conocida como El Plan; sus redes se dibujan providencialmente de esa misma manera. Históricamente Valparaíso planteaba una red de transporte eléctrico en la explanada, los tranvías, conectada por ascensores, también eléctricos, en lo radial hacia los cerros. Este pensamiento surgido de la lógica geográfica establecía una razón y fundamento claro para su trama de transportes. Actualmente las formas de comunicar esos radios en altura con el centro común consisten en una ruidosa, ineficiente, complicada, y por ende insustentable red de transporte colectivo que funciona a petróleo. Esto indica un abandono irresponsable de la planificación del transporte en la ciudad; durante tres décadas se dejó este desarrollo a las llamadas fuerzas del mercado, en el paradigma de la libre competencia. Fuerzas que al buscar, sin coordinación de la ciudad, maximizar las ganancias en el corto plazo, pasan por sobre cualquier planificación posible.

Considerando otra trama de redes superpuesta a la anterior, se puede además afirmar que Valparaíso conserva el concepto de barrio, un lugar de redes donde es posible llegar al almacén, al colegio y el taller sin pérdidas de tiempo, en un ámbito conocido, familiar y comprensible. Este es un punto en que los habitantes locales reconocen el respeto por la escala humana que tienen los cerros de la ciudad. Nada más lejos de esta realidad que, por ejemplo, un Mall en las afueras donde sólo se llega en el ineficiente y clasista automóvil. El barrio es así muy eficiente en energía, puede administrar muy bien sus redes funcionales. En la trama de transporte ciudadano existe allí el eficiente traslado a pie, tiene un tráfico vehicular restringido, a veces casi nulo.

\section{Transporte}

Hay algo en el antiguo concepto de los ascensores que podría evitar a futuro los millones de explosiones de gasolina que conforman hoy la contaminación atmosférica y el ruido de fondo de 
la ciudad. El concepto de los ascensores porteños es en sí patrimonial. Extender dicho concepto hacia lo alto del anfiteatro, agregaría interés a la ciudad y la haría ingeniosamente eficiente. Aquí hace falta soñar tecnología y tomar decisiones políticas adecuadas. Está demostrado que una ciudad eléctrica, por dar un ejemplo, es mucho más sustentable en lo físico que una ciudad que funcione con combustibles carbonados en su interior. Pero además, una ciudad eléctrica, por eficiencia, bajo nivel de ruido y comodidad resulta más amable que cualquier otra. Es probable que la tecnología necesaria sea una de alto estándar, basada en sistemas y tamaños diferentes de los que hoy impulsan los ascensores. Sin embargo el concepto es patrimonial y aporta a todas luces a sustentar la ciudad, su imagen y su amabilidad.

Como dato asociado es necesario comentar que un motor de combustión interna, relativamente bien mantenido, usado hoy en día en los automóviles, colectivos y buses de la ciudad actual, tiene una eficiencia cercana al 30\%, eso en el motor bien afinado, sin aún pasar el torque por la caja de cambios y llegar a las ruedas. En este caso el resto de la energía de la combustión de petróleo y derivados, $60 \%$, se convierte en contaminación, ruido y desgaste de piezas. Según los informes de la Comisión Nacional de Energía ${ }^{4}$, Chile actual depende en un 39,5\% de petróleo importado y el transporte urbano porteño, a excepción de unos decadentes troles, pocos ascensores y un tramo del metrotrén, se hace casi un 100\% con petróleo ${ }^{1}$, lo que lo hace sucio y dependiente. Por el contrario, un motor eléctrico puede comunicar el 98\% de su energía a las ruedas sin necesitar caja de cambios, de allí que el transporte eléctrico, con electricidad producida incluso sin contaminación atmosférica, resulta hoy en día el ideal para una ciudad sustentable y eficiente.

En el caso de la ciudad de Santiago, y su ya crítico programa Transantiago, que muestra cómo la persistencia política del petróleo y sus derivados, incluido el gas natural, como prioridades energéticas, resultan en un smog incontrolable, una alta dependencia económica e internacional de energías sobre las que no tenemos dominio alguno como país, menos aun como ciudad. Santiago a petróleo es el paradigma mismo de la insustentabilidad, la atmósfera irrespirable y su compañía lógica: mala calidad de vida de los habitantes. En estos momentos la diferencia entre Santiago y Valparaíso en este punto es que efectivamente esta última tiene mejor ventilación.

4 CNE, Anuario Estadístico 2007, Editado por CNE, Santiago de Chile, Página Electrónica de la Comisión, Energía sector Comercial Público Residencial. 


\section{La edificación}

Una ciudad eficiente en energía, contempla un modo de edificar, un uso de los materiales y una manera de inserción de sus edificaciones, que hacen buen uso de la oferta solar y de la oferta de sus vientos. También inteligentemente, se protege de los temporales, las lluvias y el frío, y gracias a los desarrollos tecnológicos de las últimas décadas, una ciudad del siglo XXI debería aprovechar eficientemente la oferta geotérmica de su propio subsuelo inmediato.

De algún modo la arquitectura más antigua de Valparaíso escoge elementos que hoy en día podrían reconocerse como solares pasivos; tales como las galerías, los muros de tabiquería de maderas nobles, rellenos con adobillo hecho de barro y paja, asísmicos, térmicamente inerciales y equilibradamente aislantes, cubiertos de latón acanalado importado; también están los techos con grandes cámaras de control ventiladas y los ventanales controlados con postigos. La ciudad providencialmente apunta globalmente al norte y hacia el oceánico paisaje. Por la pendiente se facilita para todos el acoger el arco solar cotidiano, una ventaja que no presenta otra ciudad de Chile. En todos lados del Valparaíso patrimonial se recogen formas arquitectónicas de ampararse del viento y esquivar los torrentes de las aguas lluvias. Todas estas actitudes ya vernáculas de la arquitectura y la ciudad se acercan bastante a lo que plantea la bioclimática moderna.

Existen en los ya mencionados muros de la tabiquería de maderas nobles, rellenos con adobillos, en las casas de tres pisos de los cerros más emblemáticos del centro de Valparaíso, que además han resistido al menos tres terremotos importantes, bien aplicados conceptos de inercia, aislamiento y ventilación, rescatables a la luz de la necesidad de desarrollar nuevos materiales y sistemas para lograr una propuesta más energéticamente eficiente.

Hoy en día desarrollar una edificación eficiente en energía ocupa un lugar importante en los planes del país en cuanto a su sustentabilidad nacional. El sector Comercial, Público y Residencial consume el 27\% de la energía total de Chile, perdiendo del orden del 35\% de la energía que insume, lo que representa una muy mala eficiencia energética. El factor culpable fundamental apunta a fallas en el diseño y construcción. Una edificación eficiente parte por reconocer desde su diseño las cualidades del clima, el suelo y sus habitantes, con vistas al mínimo uso de energía, para el máximo resultado de la misma. La sustentabilidad encuentra en este pensamiento energético un punto insoslayable y hay mucho de la arquitectura de Valparaíso que puede mejorarse y rescatarse para ello. En una edificación inteligentemente eficiente, la calidad de vida es mejor, no sólo en lo económico, y el existir en ella resulta por lo tanto más amable. 
Es probable que en un futuro cercano Valparaíso aproveche sus alturas y los vientos dominantes del sur suroeste que en ellas soplan, para establecer parques eólicos que alejen definitivamente los fantasmas del petróleo. Los grandes molinos de viento, coronando el paisaje sin llegar a destruirlo, pueden ser en el futuro parte importante del patrimonio de la ciudad y un símbolo visible de su sustentabilidad energética. Lograr que el viento suba y baje a sus habitantes, impulse sus actividades productivas y los ilumine por las noches, puede ser el acto de desarrollo más ambientalmente coherente y simbólico que el futuro guarde para Valparaíso.

\section{Patrimonio verde}

Otro asunto importante a considerar en una ciudad sustentable es la muy antigua relación que existe entre la humanidad y las áreas verdes. La áreas verdes en el contexto urbano amortiguan el ruido, ayudan a la infiltración de las aguas, mantienen el suelo en su lugar en las pendientes, recirculan el oxígeno, sostienen la biodiversidad, dan sombra, regulan los vientos y sobre todo, tienen un arraigo psicológico profundo con nuestra sensación de bienestar y la conservación de la salud. La OMS, Organización Mundial de la Salud, recomendó hace muchos años que cada habitante urbano del planeta debiera tener acceso al menos a nueve metros cuadrados de áreas verdes consolidadas. Se entiende en este artículo que las áreas verdes urbanas consolidadas son algo más que simples prados y algo más que lejanas forestaciones productivas. Se considera en esta definición que las áreas verdes dentro de los límites urbanos deben ser abiertas, arboladas y con equipamiento de uso público. Tal como acota Waldo Ceballos en su texto Enverdecimiento Urbano de Chile, las áreas verdes son "para proporcionar goce visual, esparcimiento y bienestar a sus habitantes". ${ }^{5}$ Valparaíso presenta una notable carencia al respecto, lo abigarrado y compacto de sus barrios no pareciera admitir más árboles, ni plazas más frondosas. Gran parte de las casas no tienen patios ni jardines. De acuerdo a la población actual censada, Valparaíso debiera tener al acceso equilibrado de su población al menos 216 hectáreas de áreas verdes consolidadas y equipadas. El equivalente a 216 manzanas convertidas en plazas o parques, algo que hoy evidentemente no existe.

Sin embargo, Valparaíso tiene en su topografía un hecho salvador: Sus quebradas son abundantes, son 42 las más importantes y en muchas partes suelen ser frondosas y ricas en flora nativa, existe una biodiversidad remanente y otras cualidades de

5 Ceballos I. Waldo, Enverdecimiento urbano de Chile, Ediciones Krishnamurthy L. yJ. Rente Nascimento, Santiago, Chile, 1997, pag. 233. 
la foresta que se pueden potenciar positivamente, rescatando un carácter propio de Valparaíso. Las quebradas son parte de la historia de la ciudad y normalmente acogen a sus habitantes más postergados. Las quebradas hoy en día están allí como espacios remanentes difíciles de urbanizar, sólo los más osados habitantes, entre los carentes de vivienda, logran colonizar una toma habitable en esas pendientes.

Las quebradas de Valparaíso sufren, entre otros, dos problemas importantes que afectan su sustentabilidad, el primero corresponde a los incendios de su gran carga térmica vegetal, azuzados por el efecto chimenea que aporta su geografía particular, y el segundo es la basura. Los habitantes ante el mal sistema general de disposición de residuos domiciliarios, residuos volumétricos, tales como neumáticos, cocinas, autos, lavadoras viejas y escombros de construcción, utiliza las quebradas para deshacerse de ellos, empleando simplemente la fuerza de gravedad que tiende a llevar todo al lecho de la misma.

Las quebradas aún verdes de Valparaíso son potencialmente parques y plazas de uso público insertas precisamente entre los límites de cerros y barrios. He aquí un proyecto posible de realizar en la Ciudad: Limpiar, planificar participativamente e implementar del mismo modo, las quebradas remanentes como áreas verdes consolidadas. Un gesto ciudadano de estas características y estas dimensiones, rescataría un elemento patrimonial antiguo de Valparaíso cual es su complejo de quebradas. Es más, las quebradas permiten regular perfectamente las aguas lluvia de la ciudad. Existen en algunas quebradas complejos de tranques de regulación para evitar los aluviones hacia el centro de la ciudad. Las quebradas indudablemente son un elemento estructural profundo de la ciudad, son parte de su imagen y por supuesto la sustentabilidad está también asociada a la planificación y mantención de las mismas.

Dentro de lo que hoy se llama ecología urbana surgen nuevas relaciones entre la vida y el medio, relaciones que se dan en el territorio no natural, artificialmente cubierto de las ciudades humanas. Existen allí especies de flora y fauna nativa que logran subsistir en las nuevas condiciones, y existen especies de flora y fauna introducida que muchas veces compiten con las anteriores; estas nuevas relaciones entre las especies vivas y el territorio artificial de las ciudades, generan la ecología de lo urbano. Esto corresponde al desarrollo de un nuevo capítulo de la biodiversidad, que se adapta al lugar intervenido por la organización humana. Este es un punto importante a estudiar y analizar en el contexto del patrimonio y en el contexto de la sustentabilidad. Los habitantes humanos de Valparaíso coexisten con otras especies vivas domésticas y no domésticas, de esa relación surgen además arraigos, amores y desamores. 
La ciudad de Valparaíso tiene en sus quebradas un potencial verde $\mathrm{y}$ de hábitat animal que la diferencia de muchas otras ciudades. Las quebradas no son paños de la trama urbana planificadas como plazas o parques, son rezagos de la geografía primigenia que existía para la fundación. Hoy en día están las quebradas de Valparaíso a muy mal traer y con fauna indeseada, como los ratones grises que desplazan a otros animales y generan problemas de salubridad. Sin embargo las quebradas a todas luces representan una enorme oportunidad en el logro de la sustentabilidad de la ciudad.

\section{El legado de Santa María}

Federico Santa María Carrera, filántropo chileno, que precisamente hace la donación fundacional de la Universidad Santa María, donó en 1915 a la entonces Junta de Beneficencia de Valparaíso, 1400 hectáreas de un gran fundo que limita al sur de la ciudad, con la intención, entre otras, que allí se construyese un "gran parque arbolado a la usanza europea de la época”. Donación, que aparece en libro homenaje de Agustín Edwards ${ }^{6}$, fue hecha con una excepcional visión ambiental de

6 Edwards, Agustín, Apuntes Biográficos de Don Federico Santa María, y Breve Noticia de la Fundación que lleva su Nombre, Editor, Colouma, Hbarthelemy, Paris Francia 1931, pag. 14. futuro, en una época donde el asunto ambiental no estaba en el tapete del desarrollo. La donación quedó guardada durante más de 80 años y nunca se realizó la condición testamentaria de la misma. La donación pasó por los archivos de diferentes instituciones herederas de la Junta de Beneficencia de Valparaíso, hasta que llega por transferencias a lo que hoy a principio del siglo XXI se conoce como FONASA, Fondo Nacional de Salud, entidad que además no está estatutariamente habilitada para desarrollar parques. Hoy en día, luego de casi un siglo de olvido, el legado está en poco más de $700 \mathrm{Ha}$, Sucesivas expropiaciones han ido disminuyendo la superficie. Más todavía podría llegar a ser uno de los parques urbanos más grandes del país.

Con un gran esfuerzo de coordinación la actual administración de FONASA ha logrado concertar los intereses de diversas instituciones con el fin de concretar el legado de Federico Santa María. Entre estas instituciones está el CRUV, Consejo de Rectores de Valparaíso, que está formulando la "Fundación Interuniversitaria" que tendrá por misión concretar parte del sueño de Santa María. 
Este precisamente se constituye en uno de los patrimonios ambientales más importantes de la Ciudad de Valparaíso. El destino actual de esta visión de don Federico para con su ciudad Valparaíso, es precisamente establecer una estrategia altamente sustentable para el proyecto parque. La sustentabilidad de este patrimonio verde es el eje principal de todos los proyectos en curso, proyectos donde las escuelas de Arquitectura de la UTFSM; UV y UCV tendrán un gran protagonismo. En 2007 se logró el estatus de Santuario de la Naturaleza para los ocho kilómetros de acantilados marinos que parten en Valparaíso y llegan a Laguna Verde. En 2008 se ha propuesto incluir esta zona dentro de la nueva reserva de la Biósfera presentada por el gobierno de Chile a la UNESCO. La concreción de este parque se espera colabore con un buen soporte a la sustentabilidad social y ambiental de Valparaíso en los próximos siglos.

\section{Participación}

Este es un punto no menor, finalmente quienes harán sustentable a Valparaíso serán siempre sus habitantes. La participación ciudadana bien articulada, informada e instrumentalizada, es un eje fundamental de la sustentabilidad. El crecimiento histórico de la ciudad se enracima en las intervenciones de muchos arquitectos descalzos, en el sentido que describe Van Lengen en su ya clásico libro ${ }^{7}$, y el aporte de algunos arquitectos profesionales, que fueron conquistando sus cerros alejados de una planificación urbana tecnificada y cuyo resultado ha sido coherente por el simple hecho de que la topografía determina con mucha claridad por dónde se puede habitar.

El resultado global de esta suma histórica de intervenciones de sus habitantes, es precisamente lo que determina en gran parte la actual situación patrimonial de Valparaíso. Valparaíso ha sido una de las ciudades de Chile que ha recibido más participación de sus ciudadanos en la forma que se ha ido implementando en el tiempo. Hoy Valparaíso en muchas partes envejece y es precisamente la participación ciudadana la herramienta que permitirá la conservación de sus edificaciones patrimoniales, el carácter de sus barrios y la coherencia que deban tener las nuevas edificaciones que surjan. Las generaciones futuras seguirán sustentando su ciudad en la medida que esta siga siendo apropiada y apropiable por sus decisiones consensuadas. Esto involucra además aplicar el concepto de democracia en los procesos de participación. La participación que aquí se habla no es la eleccionaria, sino aquella que hoy

7 Van Lengen Johan: Manual del Arquitecto Descalzo: cómo construir casas y otros edificios, Editorial Pax México, 2002 cop. Pag. 62. 
se reconoce como proactiva, aquella en que los habitantes generan informadamente las ideas, colaboran en tomar las decisiones, usan la palabra, participan y evalúan en la acción. Vale decir una participación financiada, habilitada estructural y políticamente por la ciudad.

La participación ciudadana es un asunto que genera una gran deuda en la forma en la que actualmente se gobierna la ciudad, no solo Valparaíso sino que la mayor parte de las comunas de Chile. El gobierno de la ciudad en Chile está dominado por lo grandes grupos de cabildeo, mejor conocido como "lobbies", incluso apareció y se entronizó en el lenguaje político el término "lobbista". Por la estructura política y económica general del país, dominada hoy por la economía de mercado, los grupos de mayor poder son aquellos que concentran mayor cantidad de dinero e inversiones. Aquí se destacan los conglomerados inmobiliarios, las grandes empresas que muchas veces, por sobre las regulaciones de planificación urbana o usando resquicios no contemplados en las mismas, construyen en la ciudad edificios que rompen con cualquier cuidado patrimonial de su contexto:

En 2006 un supermercado logró colocarse en una esquina a un costado de la iglesia La Matriz, en pleno centro patrimonial de la ciudad, ganando una larga pelea judicial entre organizaciones ciudadanas y la empresa, conflicto que se desarrolló entre 2000 y 2007. Otro edificio de tiendas y supermercado se levantó en el nudo principal del acceso sur de Valparaíso, construyendo su estructura principal delante de un ascensor al cerro Barón, obstaculizando su acceso y visual, inhabilitándolo completamente. Este nuevo centro comercial demolió e hizo desaparecer las instalaciones de la más antigua compañía de gas de Chile, un posible monumento que nunca llegó a serlo. Ambos casos significan el triunfo del sistema inmobiliario empresarial, por sobre las consideraciones ciudadanas, y, por supuesto, levantan dudas sobre las posibilidades de la defensa de la sustentabilidad del patrimonio de la Ciudad cuando esta está sometida al mercado.

No hay duda que la participación ciudadana resulta fundamental para desarrollar la ciudad que los habitantes aspiran. Sin embargo, la real participación requiere de factores que aún no se construyen en Valparaíso (y en Chile), tales como su habilitación como instancia estructurada, el manejo democrático y transparente de la información, el desarrollo de una cultura participativa, y lo más importante: que los resultados de la participación sean efectivamente reflejados en políticas y decisiones. Dado que la experiencia actual ha sido el abrir una participación poco estructurada que al final no se refleja en ninguna parte, más bien las decisiones importantes del hacer ciudad igual se toman bajo el lobby del concentrado poder económico actual. Con estos resultados la gente 
deja de creer en la participación como herramienta de opinión y control ciudadano.

Por el lado positivo y proactivo de la ciudadanía, algunos sectores de Valparaíso ofrecen los resultados del accionar de pequeños grupos ciudadanos que, de modo organizado, están rescatando sus entornos verdes. Este es el caso del TAC, taller de acción comunitaria que logró establecerse en una quebrada del Cerro Cordillera, abriendo un espacio comunitario vinculado a la participación social y el cuidado del entorno, concentrado en el uso sustentable de una quebrada. Con virtudes y defectos esta experiencia demuestra las posibilidades de la participación ciudadana en la construcción del espacio físico y social donde la propia gente habita.

Año a año las quebradas deforestadas y llenas de basuras de Valparaíso son la causa de, muchas veces, mortales aluviones en períodos de lluvias. No es difícil desarrollar un programa participativo para la gestión, uso, recuperación y control de las quebradas porteñas, solo falta aquí imaginación, planificación y un contundente apoyo político a largo plazo, que traspase los periodos del poder transitorio de un gobierno municipal.

\section{El mar y el borde mar}

Entre otros muchos puntos, resulta inevitable referir aquí la muy antigua relación de Valparaíso con el Océano Pacífico. Buena parte de la situación patrimonial de Valparaíso surge del océano más grande del planeta y el tránsito de la humanidad por él. Alguna vez fue uno de los puertos más importantes del mundo y en su estructura física y social guarda el recuerdo de inmigrantes de muchas tierras. Hoy en día el Pacífico vuelve a mostrarse como un espacio de encuentro universal, apareció la APEC, ante lo cual Valparaíso puede encontrar un nuevo motor de desarrollo que indudablemente afectará su situación patrimonial y. por supuesto, sus expectativas de sustentabilidad. Valparaíso, como muchas ciudades costeras, tiene esa especial característica de poseer una frontera abierta que la hace permeable y transparente desde las aguas. El puerto y la ciudad tienen una clara lectura desde la relación de comercio, viajes e intercambios que surgen desde el océano. El desafío actual de la APEC para Valparaíso está en el poder responder a las demandas del comercio marítimo global, definiéndose como puerto internacional que haga converger el comercio oeste de Chile y la República Argentina con el gran área Pacífico. Existe la posibilidad, aún especulativa, de un mega puerto entre Quintero y San Antonio. Lo importante en esto es poder imaginar los escenarios posibles y cómo afecta esta expectativa en la sustentabilidad de la ciudad.

Las experiencias de la ciudad con el mar no han sido siempre buenas. Esta misma relación comercial con el mar permitió en la última mitad del siglo 
XX que los habitantes de Valparaíso perdieran su acceso al mar. Ese mar que actualmente se mira pero no se toca, debido a una continua barrera de contenedores, líneas de tren, carreteras, rejas y áreas restringidas, que niegan el borde por varios kilómetros a los ciudadanos comunes. Valparaíso intenta en estos años recuperar su borde costero para el uso público, esto entra en conflicto con la presiones del mercado del tráfico marítimo, que estima que mientras más cerca estén los contenedores y bodegas del mar, más barato y eficiente será el negocio. Existen hoy proyectos de inversión privada, condominios, hoteles, marinas y comercios, terminales de cruceros. Todos han sido mal sometidos a participación ciudadana, de avanzar ciertas propuestas, podrían llegar a privatizar el borde mar de Valparaíso. Indudablemente el punto está en que buena parte de la amabilidad futura de la ciudad se establece en las relaciones del habitante con el mar y eso estará permanentemente en juego.

\section{Al final}

También la arquitectura de hoy tiene el desafío de crear el patrimonio arquitectónico para los próximos siglos. La ciudad no es estática en esto y es difícil imaginar la ciudad del siglo XXII pensando hoy en qué podrá ser considerado patrimonial de Valparaíso en cien años más. Tal vez sea el nuevo sistema de ascensores gravitacionales o el viejo sistema eólico del siglo XXI que aún suministra energía eléctrica a la ciudad, un nuevo concepto de barrio o el sistema único de quebradas sustentables.

Por ahora, en el corto plazo, pareciera que la línea del tren está por caer o sumergirse, y el borde mar puede ser conquistado de nuevo por los ciudadanos, al salir de allí los bloques de cuatro o más pisos de contenedores. Los enormes espacios que allí se generan van a despertar una nueva y pujante relación del habitante con su mar. Esto va a mejorar las condiciones humanas para la sustentabilidad de Valparaíso. Es probable que también la ciudad gane terreno al mar; históricamente, cuando a Valparaíso le va bien, entonces le gana terreno al mar extendiendo hacia adelante el borde costero. También es posible que Valparaíso cuente con las 700 hectáreas de parque urbano Santa María en el futuro de las conurbaciones que se esperan para el siglo XXI.

Los desafíos de la ciudad y sus ciudadanos en la búsqueda de su sustentabilidad son por ahora recuperar el mar ciudadano, usar intensamente energías renovables, recuperar la biodiversidad de las microcuencas urbanas, aumentar las densidad de los espacios verdes, extender el transporte eléctrico vertical, reconocer los límites y los patrones sociales y físicos de habitabilidad de la ciudad y desarrollar la participación de los ciudadanos en función de mejorar estos. 
Estos procesos posibles configuraran virtualmente aún el conjunto de regalos más importante que podemos dejar para que las generaciones futuras amen más a Valparaíso, Valparaíso se torne sistémica y socialmente más amable y de ese modo se logre hacer sustentable a la ciudad en los próximos siglos.

\section{Bibliografía}

BLUNDELL-JONES; PETRESCU, Doina Peter; TILL Jeremy; BLUNDELL-JONES Peter. Architecture and Participation, lera ed.,Taylor \& Francis, Londres, UK, 2005, 282 pág.

CALDERÓN, Squadrito; SCHLOTFELDT, Marilis. Memorial de Valparaíso, en los 450 años de su descubrimiento: lera ed., Valparaíso, Chile,Ediciones Universitarias de Valparaíso, Universidad Católica de Valparaíso, 1986, 491 pág.

CNE, Anuario Estadístico199-2007, Comisión Nacional de Energía, lera ed. Santiago, Chile, CNE, 2007, 215 pág.

CARBONELL Blanco, José Antonio, et al. Somos patrimonio. Vol. 5: 361 Experimentos de Apropiación Social del Patrimonio Cultural y Natural, $1^{\text {a }}$ edición, Valparaíso, Chile, Ed. Convenio Andrés Bello, 2006, 376 pág.

DOWNING, Sandra L. Asia Pacific Economic Cooperation (APEC): Current Issues and Background, lera ed.,
Nueva York, USA Nova Cience Publishers, 2003, 193 pág.

EZRA Park, Robert; MARTíNEZ Emilio. La Ciudad y Otros Ensayos de Ecología Urbana, $2^{a}$ edición, Barcelona, España, Ediciones del Serbal, 1999, 148 pág.

MARTIN Palmero, Federico; Desarrollo Sostenible y Huella Ecológica/ Sustainable Development and Ecological Marks, lera ed. Madrid, España. Netbiblo Sl, 2004, 239 pág.

MELE Patrice; HENNEQUIN Jean. La producción del Patrimonio Urbano, lera ed., Francia, CIESAS, 2006, 425 pág.

MONTEZUMA, Ricardo. Ciudades Amables, Reflexión sobre Movilidad Urbana y Sustentabilidad en América Latina. Documento presentado a ler. Congreso Internacional de Transporte Sustentable Ciudad de México D. F., Bogotá, Colombia, Edición Fundación Ciudad Humana, 2005.

PIATTI, Alberto; SZËGO, Edoardo. Planning of Geothermal District Heating Systems, ler ed., Berlin, Germany, Springer, 1992, 336 pág.

SERRANO, Pedro. Bioclimática en Valparaíso, ler ed, int. Valparaíso, Chile, Arq UTFSM, 2007, 74 pág.

STEHELIN, Paul H. The Electric City: The Stehelins of New France 2a ed. Paris, Francia, editado por Lancelot Press, 1983, 276 pág. 